\title{
Contamination of virological tissue cultures with a species of free-living soil amoeba
}

\author{
DAVID P. CASEMORE \\ From the Department of Virology, Public Health Laboratory, General Hospital, Middlesbrough
}

SYNOPSIS Overwhelming contamination of a continuous cell line with a free-living soil amoeba of the genus Hartmannella is reported. The significance of the finding is discussed because of recent $\frac{?}{8}$ interest shown in the role of this and related species of amoebae in disease of humans. The methods $\underset{N}{N}$ used to detect and identify the amoeba are described and some examples of the amoebae are shown $\omega$ by photomicrographs. The use of metronidazole to eliminate the amoeba from tissue culture is also $\mathrm{N}$ described. This procedure has proved successful in practice although the empirical basis for it has not been confirmed by direct assay. Consequently, there is a need to test possible alternative chemical regimens.

Attention has been drawn in recent years to two species of amoebae, Hartmannella and Naegleria, which have been associated with disease in man: pyogenic meningitis (Fowler and Carter, 1965; Butt, 1966; Červa and Novăk, 1968); respiratory infections (Pereira, Marsden, Corbitt, and Tobin, 1966; Armstrong and Pereira, 1967); and infective hepatitis (Chang, Pan, and Rosenau, 1966). When reporting on one such amoeba, Warhurst and Armstrong (1968) considered it unlikely that the protozoa had been derived from inherent or accidental contamination. They did point out, however, that the detection of amoebae of obscure origin in mammalian tissue cultures had been reported on several occasions. However, it is probably not widely recognized that amoebae may be a cause of progressive degeneration of tissue and cell cultures.

\section{INVESTIGATION OF TISSUE CULTURE DEGENERATION}

In September 1967 an unusual form of progressive degeneration was noted in random tube cultures of HeLa cells at this laboratory. Because the numbers of such affected tubes rapidly increased, attempts were made to discover the cause.

VIRUS CULTURE In an attempt to obtain a recognizable cytopathic effect, tissue culture fluid was passed to several different cell cultures: secondary rhesusmonkey-kidney, WI 38, primary human amnion, primary human foetal lung, primary human foetal

Received for publication 30 August 1968. kidney, and HeLa. In most instances some cytopathic effect was obtained, although this was not characteristic of the common cytopathogenic viruses. Attempts to neutralize the effect with a wide range of antisera were unsuccessful.

MYCOPLASMA CULTURE Cells were cultured for mycoplasmas according to the methods recommended by Dr B. E. Andrews of the Mycoplasma Reference Laboratory, Colindale, but these failed to yield any growth. Empirical treatment with kanamycin in high dosage failed to improve the cells.

CULTURE FOR BACTERIAL ' $L$ ' FORMS Cultures made in antibiotic-free medium to detect ' $L$ ' forms of bacteria likewise failed to yield any growth.

DIRECT MICROSCOPY Some months before I had seen at another laboratory one of the cytopatho- $\bar{\sim}$ genic agents originally described as 'Ryan virus' $/$ (Pereira et al, 1966) but later identified as a Hart- N mannella amoeba (Armstrong and Pereira, 1967). ్ㅣㅇ This had been isolated from throat swabs, but had 0 not been recognized until unusual mitochondrial patterns were observed during electron microscopic $\frac{\mathscr{D}}{\Phi}$ examination of cell cultures. Optical examination $\stackrel{\oplus}{+}$ with a high-power lens revealed the true nature of the cells.

In this laboratory, optical examination with a $\overparen{D}$ high-power lens showed numerous amoeboid $\mathbb{D}$ trophozoites in wet preparations of cells removed from our HeLa culture tubes. 


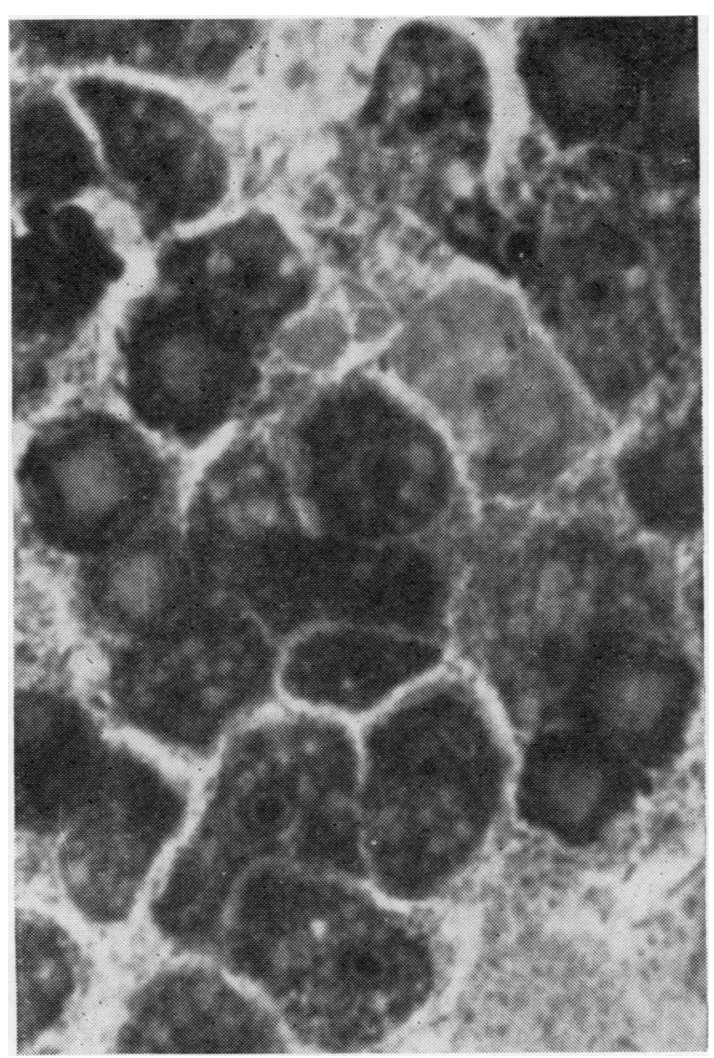

FIG. 1.

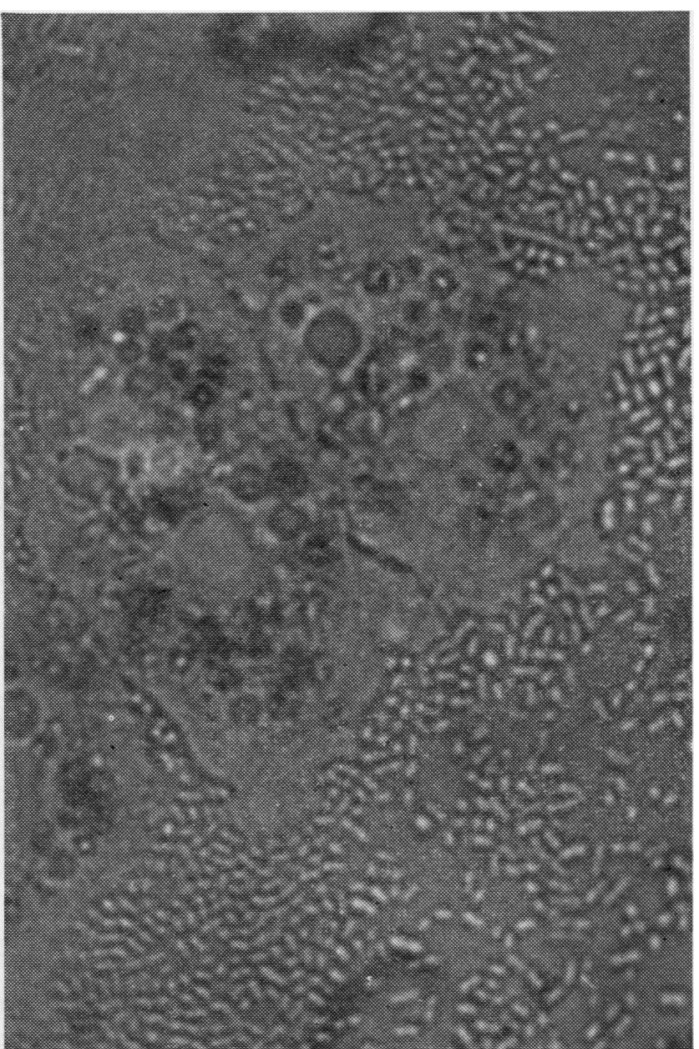

FIG. 2.

FIG. 1. Fixed agar block preparation of a Klebsiella plate culture stained with Giemsa. The field shows numerous trophozoites (diameters 12 to $30 \mu$ ) and a few cysts.

FIG. 2. Live trophozoites on agar-Klebsiella medium (both $30 \mu$ diameter).

\section{IDENTIFICATION OF THE AMOEBA}

The small, monophasic organism found had characteristics which conformed to those of the free-living amoeba of the genus Hartmannella. The trophozoites were approximately 12 to $30 \mu$, with a small nucleus containing a large karyosome. The cytoplasm contained numerous granules, and had a single contractile vacuole with a periodicity of one and a half to two minutes. This vacuole is probably the most easily detectable feature of the amoeba, although some amoebae contain non-contractile vacuoles which may be filled with ingested material. Locomotion was by lobose pseudopodia which may have numerous filiform projections. These projections are formed and retracted quite rapidly and are a characteristic of hartmannellae but not of naegleriae. Suspension of trophozoites in distilled water failed to yield a flagellar form characteristic of Naegleria when in a salt-free medium. The amoebae grew well on agar-Klebsiella medium $(1.5 \%$ agar covered with a thick lawn of Klebsiella aerogenes, previously grown in broth, washed in saline, and killed by heating at $56^{\circ} \mathrm{C}$ for $2 \mathrm{hr}$; excess moisture is removed by evaporation before the plates are inoculated with the amoebae (Warhurst and Armstrong, 1968)) recommended by Dr M. S. Pereira of the Virus Reference Laboratory, Colindale. Maximum growth occurred within 24 to 48 hours and was followed by encystment after about four days. The cysts were round at first, but slowly became smaller and deeply crenated. Cysts which have been kept at different temperatures $(+4$ to $+70^{\circ} \mathrm{C}$ ) for up to nine months have vegetated readily when placed in a suitable medium. Intranuclear changes and eosinophilic inclusions surrounded by a halo, as described by Pereira and her colleagues (1966), were detected in coverslip cultures of HeLa cells inoculated with the amoeba. The cytopathic effect produced in tube cultures of 
HeLa cells was identical to that described andshown in the photomicrograph in the same article. Dr M. S. Pereira (personal communication) confirmed that the amoeba appeared to her to be a member of the genus Hartmannella resembling those previously studied by her.

\section{ELIMINATION OF AMOEBAE FROM THE TISSUE CULTURE CELL STOCKS}

The laboratory was thoroughly cleansed and fresh cells were introduced from stocks held in liquid nitrogen. Despite these measures contamination recurred. This failure to decontaminate the laboratory led to the consideration of the use of chemicals in an attempt to suppress amoebic growth. On the advice of Mr S. L. Squires of the Experimental Chemotherapy Division of May \& Baker Limited, metronidazole at a concentration of $10 \mu \mathrm{g} / \mathrm{ml}$ was incorporated in all media to be used with uninoculated cell cultures. This regimen has now been in use for about six months, during which time the cells have been subcultured about 25 times without evidence of amoebic contamination or of toxicity. Before cell cultures are inoculated, the medium containing metronidazole is discarded, the cultures are washed in buffered saline, and a metronidazole-free medium is added to them. Cell cultures have been found to remain fully susceptible to viruses, either as stock strains or as isolates from clinical specimens.

\section{ASSAY OF ACTIVITY OF METRONIDAZOLE AGAINST Hartmannella}

To establish a rationale for the use of metronidazole, varying concentrations of the chemical were mixed with varying dilutions of a culture of Hartmannella. HeLa cultures and agar-Klebsiella plates were inoculated at varying periods of time after mixing. Incubation at $37^{\circ} \mathrm{C}$ was continued for up to five days.

An amoebicidal effect could not be demonstrated with concentrations of metronidazole up to $1 \mathrm{mg} / \mathrm{ml}$. However, some inhibitory effect was detected in several cultures which exhibited a lessened rate of division and an increased rate of encystment despite the presence of adequate nutrients. Metronidazole is widely used in treatment of trichomoniasis, and Squires and McFadzean (1962) reported that Trichomonas vaginalis is sensitive to 0.25 to $1.0 \mu \mathrm{g} / \mathrm{ml}$ in assay. Therefore, the activity of the test sample of metronidazole was assayed against two strains of Trichomonas vaginalis which were inoculated into
HeLa cell cultures (reaction adjusted to $p \mathrm{H} 6.0 \frac{\text { 을 }}{\text {. }}$ with gaseous $\mathrm{CO}_{2}$ ), containing 10 -fold varying $\vec{\Rightarrow}$ concentrations of metronidazole from 0.01 to $\stackrel{\rho}{?}$ $100 \mu \mathrm{g} / \mathrm{ml}$. Inhibition was detectable at con-? centrations as low as $0.01 \mu \mathrm{g}$ with a lethal effect at $10 \mu \mathrm{g} / \mathrm{ml}$.

\section{EXAMINATION OF THE LABORATORY AND ITS ENVIRONS FOR AMOEBAE}

The laboratory is a single storey building in the $\vec{\rho}$ centre of a large urban hospital. It consists basically of a single large room in which all virological procedures must be performed. There is a door $N$ opening directly to the exterior. Air sampling was $\omega$ carried out using a Casella slit sampler with agar- O Klebsiella medium. Ground and soil samples were cultured on agar-Klebsiella medium, on inspissated egg-locke saline slopes prepared according to Kudo $\vec{z}$ (1963), and in HeLa cells. Hartmannellae in large numbers were recovered from air and soil.

\section{DISCUSSION}

It is clear that free-living soil amoebae may be recovered in tissue and cell cultures. In order to ensure the validity of any isolation of amoebae from $\cong$ clinical specimens it is essential to exclude amoebae $\stackrel{\varrho}{\circ}$ from uninoculated tissue cultures. Continuous cell $\overrightarrow{\vec{O}}$ culture lines are known to be peculiarly prone to 3 microbial contamination, for example, with mycoplasmas, which may produce, at a sublethalo concentration, a prolonged or delayed form of degeneration.

Hartmannellae are somewhat smaller than HeLa cells and are usually only feebly motile. Consequently, as Armstrong and Pereira (1967) pointed out, they might be dismissed as $\mathrm{HeLa}$ cell fragments when viewed with the usual low-power lens by an unsuspecting observer. Amoebic contamination wouldo presumably be initiated by a few airborne cysts, and this has doubtless occurred here or elsewhere ono other occasions. The precise cause will be ascertained n only if there is an awareness of this possibility.

It is of interest to note that the episode described ${ }_{0}^{\omega}$ in this paper developed in a laboratory where the layout would seem to favour contamination from? the environment. The cellular degeneration appeared shortly after a change in staff routine, which resulted ${ }^{+}$ in more frequent movement of staff in and out of the building. An increase in dirt within the building was visible evidence of this change. It is reasonable to presume that there was a concurrent increase in 0 the inflow of amoebae from the environment.

It is fortunate that the use of liquid nitrogen? 
storage of cells is becoming more widespread, and was available in this laboratory, thereby enabling fresh stocks of healthy cells to be grown at short notice. However, continuing exposure to environmental contamination makes the use of chemosuppressants the only practical measure for preventing unwanted amoebic growth. Metronidazole appears to inhibit such growth but other compounds, for instance sulphonamides or acetarsol, are being assayed to find an effective amoebicide for use in tissue culture.

I would like to thank Dr M. S. Pereira for HeLa cells and advice, $\mathrm{Dr} \mathrm{H}$. I. Williams and $\mathrm{Mr} \mathrm{K}$. Goult for photomicrographs, May and Baker Ltd for the supply of metronidazole, Dr E. Campbell for Trichomonas specimens, Dr J. A. N. Emslie for advice, Mrs H. Grover for typing, and last, but not least, I would like to express my appreciation of the cheerful cooperation of the virology staff at all times.

\section{REFERENCES}

Armstrong, J. A., and Pereira, M. S. (1967). Brit. med. J., 1, 212.

Butt, C. G. (1966). New Engl. J. Med., 274, 1473.

Cerva, L., and Novăk, K. (1968). Science, 160, 92.

Chang, R. S., Pan, I. H., and Rosenau, B. J. (1966). J. exp. Med. $124,1153$.

Fowler, M., aAd Carter, R. F. (1965). Brit. med. J., 2, 740.

Kudo, R. (1963). Protozoology, 4th ed. Thomas, Springfield, Ill.

Pereira, M. S., Marsden, H. B., Corbitt, G., and Tobin, J. O'H (1966). Brit. med. J., 1, 130.

Squires, S., and McFadzean, J. A. (1962). Brit. J. vener. Dis., 38, 218.

Warhurst, D. C., and Armstrong, J. A. (1968). J. gen. Microbiol. 50, 207-215. 